\title{
Impact of natural organic matter on plutonium vadose zone migration from an $\mathrm{NH}_{4} \mathrm{PuO}_{2} \mathrm{CO}_{3}(\mathrm{~s})$
}

\section{source}

Melody Maloubiera, Hilary Emerson ${ }^{b}$, Kathryn Peruskia, Annie B. Kersting ${ }^{c}$, Mavrik $^{2}$ Zavarin $^{\text {, }}$ Philip M. Almond ${ }^{d}$, Daniel I. Kaplan ${ }^{d}$, Brian A. Powella,d,e

a Department of Environmental Engineering \& Earth Sciences, Clemson University, Clemson, SC, 29634, USA

${ }^{\mathrm{b}}$ Subsurface Science and Technology, Energy \& Environment, Pacific Northwest National Laboratory, Richland, WA, 99354, USA

${ }^{c}$ Glenn T. Seaborg Institute, Physical \& Life Sciences, Lawrence Livermore National Laboratory, Livermore, CA 94550, USA

${ }^{d}$ Savannah River National Laboratory, Aiken, SC, USA

${ }^{\mathrm{e}}$ Department of Chemistry, Clemson University, Clemson, SC, 29634, USA

ONLINE SUPPORTING MATERIAL

Content: 9 pages including cover sheet 


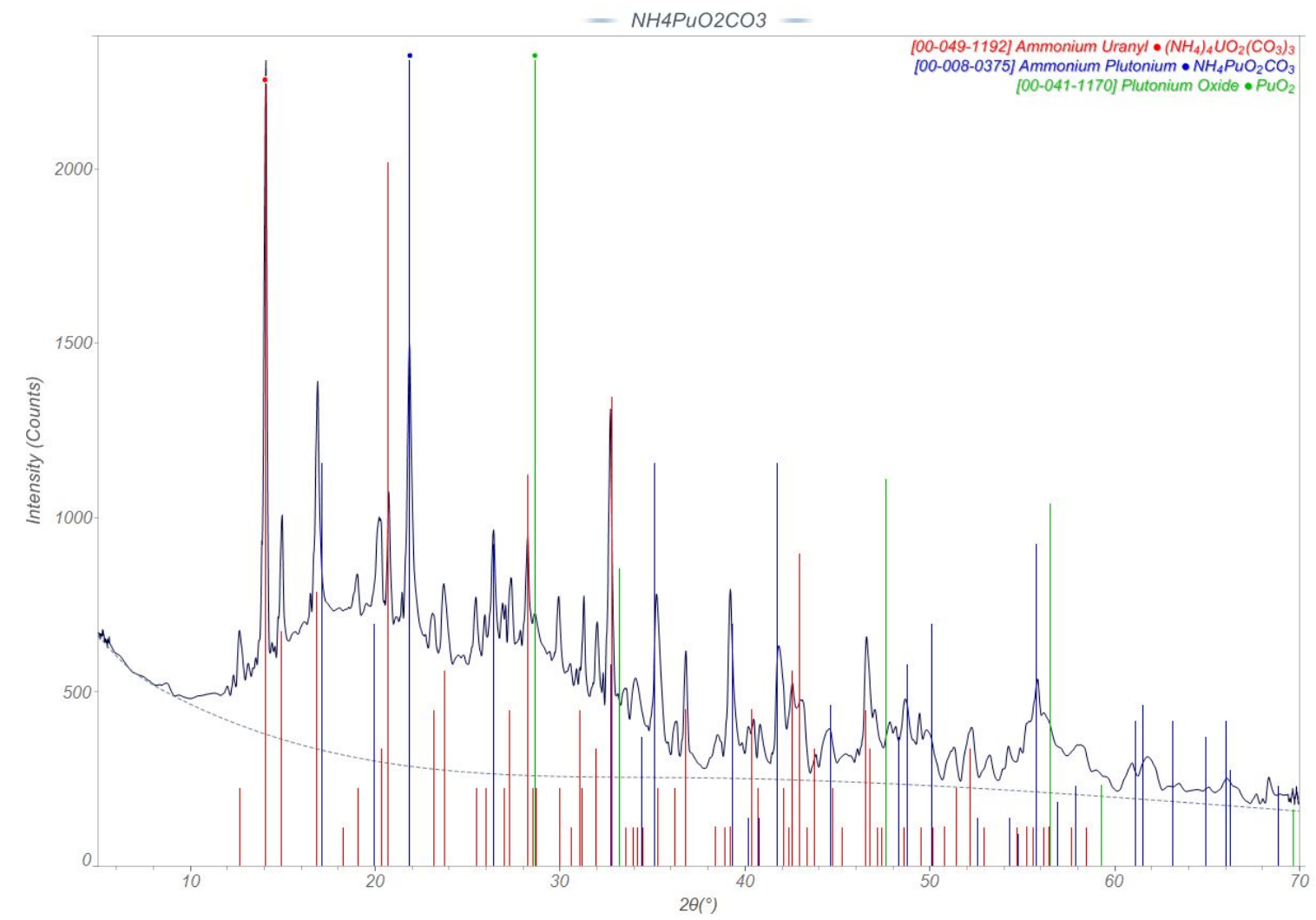

Figure S1: $\mathrm{XRD}$ patterns of the initial $\mathrm{NH}_{4} \mathrm{PuO}_{2} \mathrm{CO}_{3}(\mathrm{~s})$ realized after synthesis. 

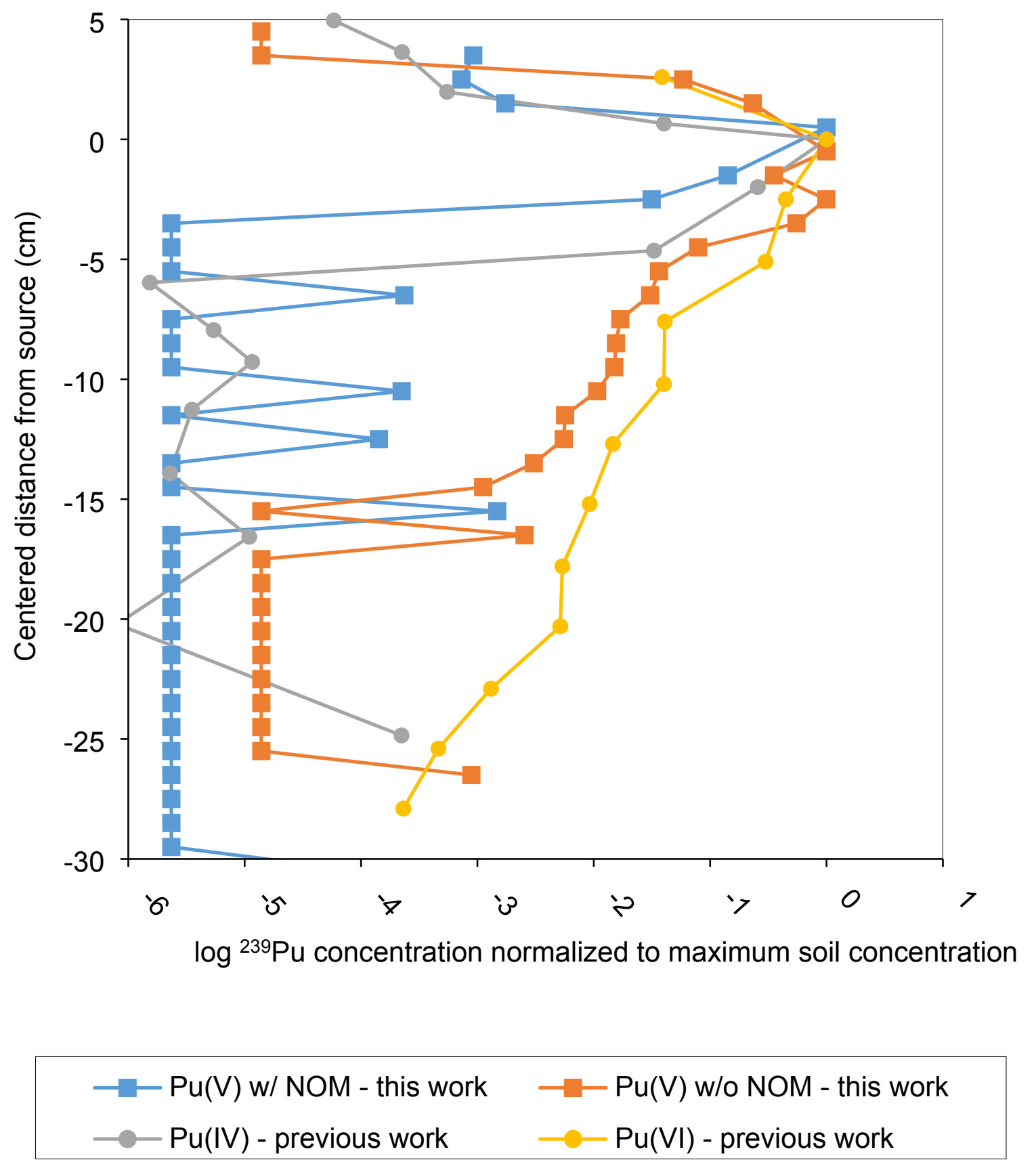

Figure S2: Normalized soil plutonium concentrations in the lysimeters containing $\mathrm{NH}_{4} \mathrm{PuO}_{2} \mathrm{CO}_{3}(\mathrm{~s})$ sources with and without organic matter as a function of distance from source. Data are compared with previous lysimeters studies deploying $\mathrm{Pu}(\mathrm{IV})$ and $\mathrm{Pu}(\mathrm{VI})$ sources reported by Kaplan et al. ${ }^{1}$. Detection limits for the $\mathrm{OM}$ amended lysimeter and $\mathrm{OM}$ free lysimeters are $2.3 \times 10^{-6}$ and $1.4 \times 10^{-5}$, respectively. 


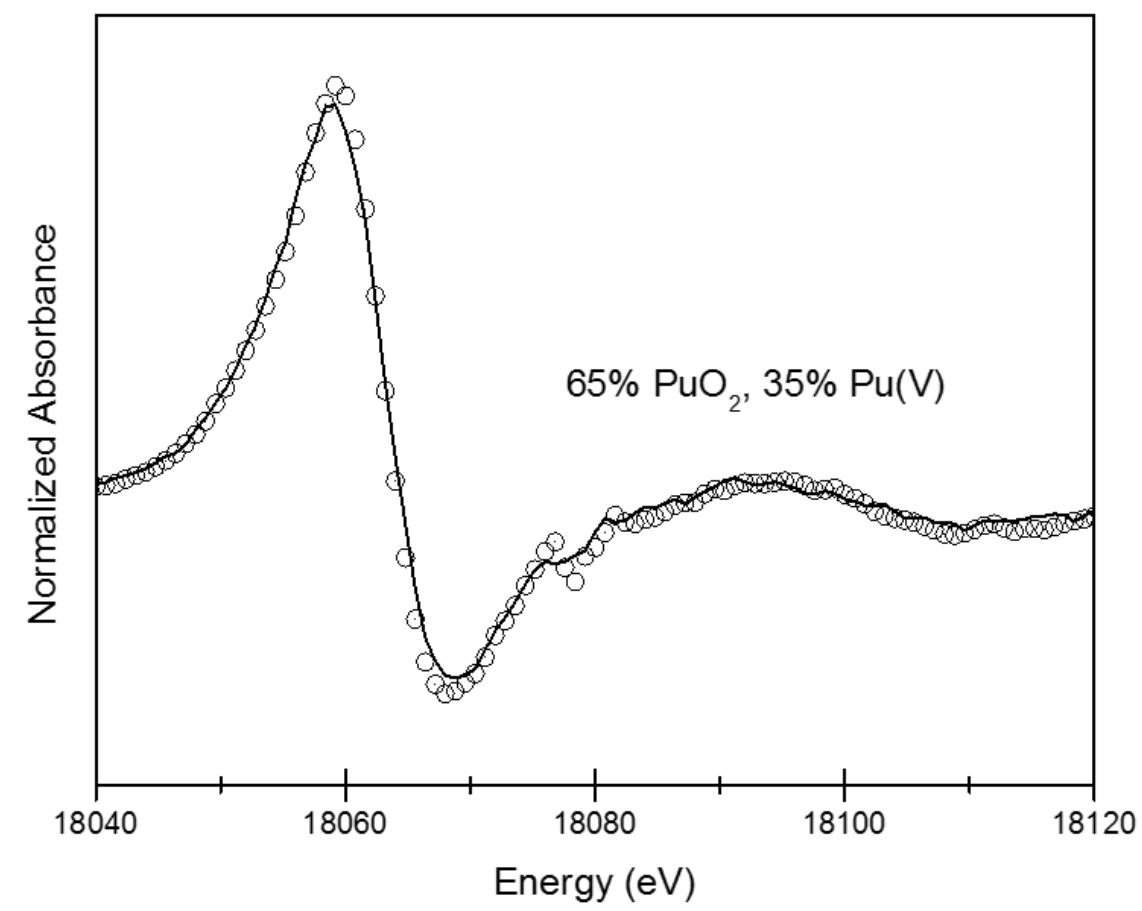

Figure S3: Linear combination fit of the normalized XANES spectrum (first derivative) of the archived $\mathrm{NH}_{4} \mathrm{PuO}_{2} \mathrm{CO}_{3}$ source after 3 years using the solvent extraction results and $\mathrm{Pu}(\mathrm{IV})$ and $\mathrm{Pu}(\mathrm{V})$ as references. Rfactor $=0.008$.

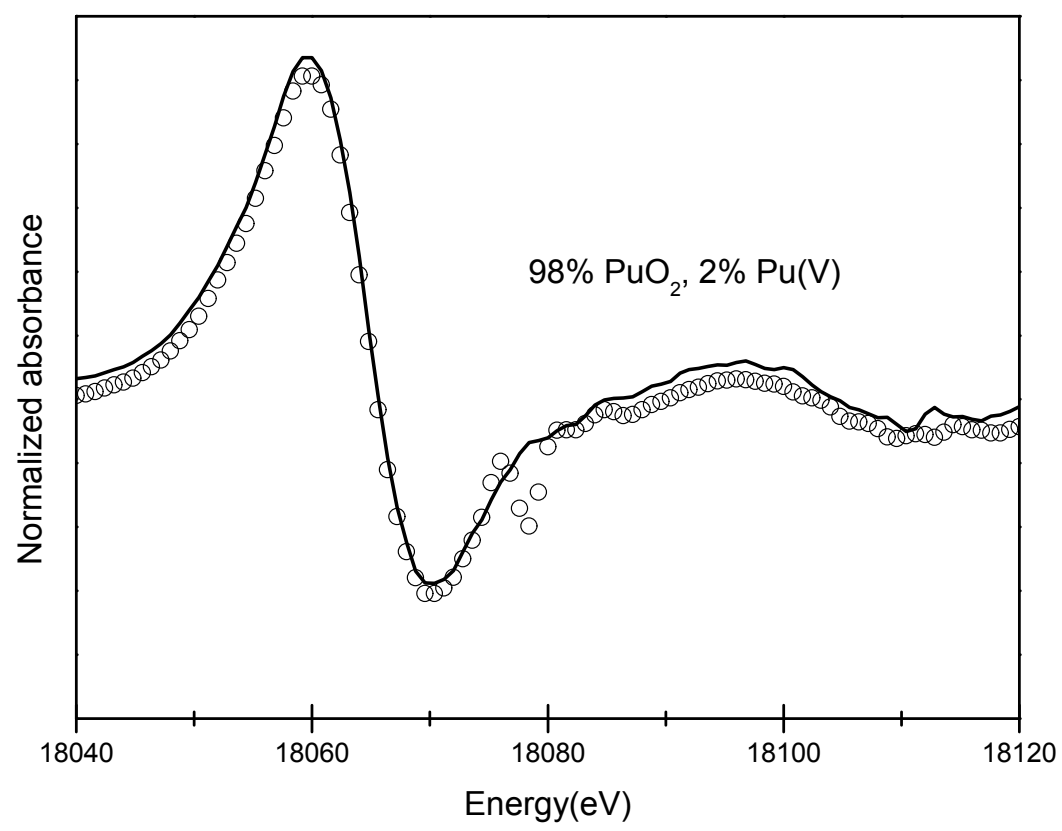

Figure S4: Linear combination fit of the normalized XANES spectrum (first derivative) of the $\mathrm{NH}_{4} \mathrm{PuO}_{2} \mathrm{CO}_{3}$ source exposed to $\mathrm{NOM}$ amended lysimeter for 3 years using the solvent extraction results and $\mathrm{Pu}(\mathrm{IV})$ and $\mathrm{Pu}(\mathrm{V})$ as references. Rfactor $=0.008$. 

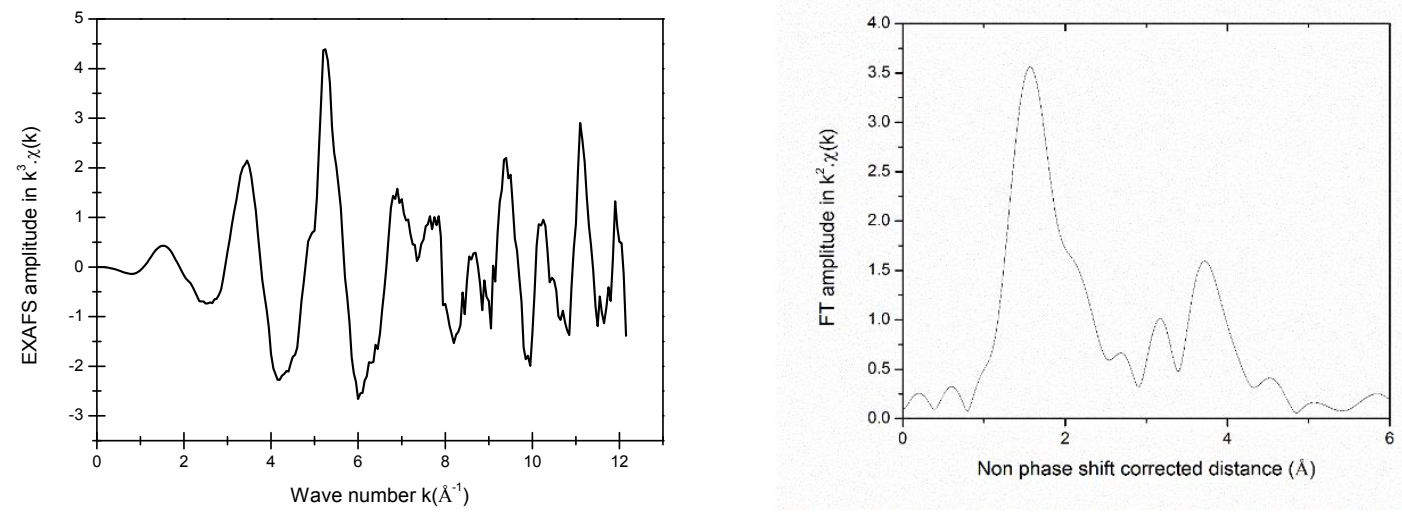

Figure S5: EXAFS spectra and its corresponding Fourier transform of the archived $\mathrm{NH}_{4} \mathrm{PuO}_{2} \mathrm{CO}_{3}$ source after 3 years of storage in an inert atmosphere.
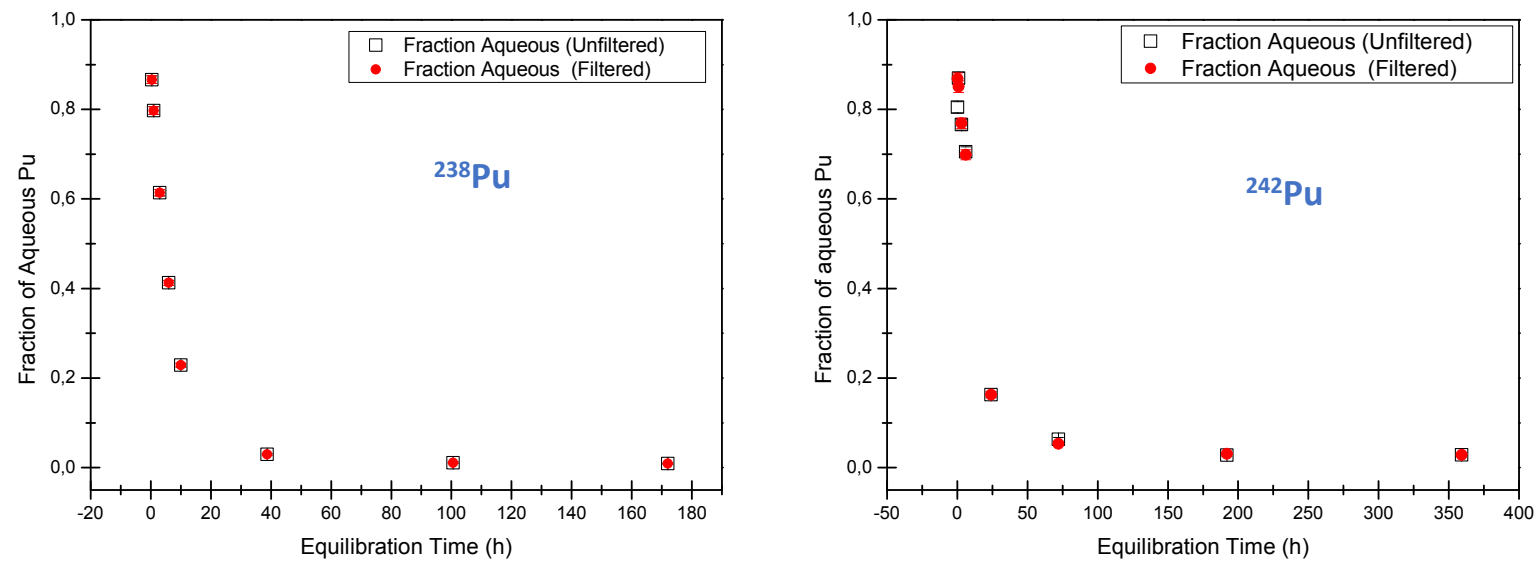

Figure S6: Percentage of Pu remaining in the aqueous phase of the unamended soil suspension, during the sorption step, before and after filtration ( $3 \mathrm{~K}, \mathrm{MWCO})$ as a function of time. The sorption was performed at $\left[{ }^{238} \mathrm{Pu}\right]=10^{-10} \mathrm{M}$ (left) and at $\left[{ }^{242} \mathrm{Pu}\right]=3 \times 10^{-7} \mathrm{M}$ (right). Suspended solids concentration $=25 \mathrm{~g} \cdot \mathrm{L}^{-1}$ 


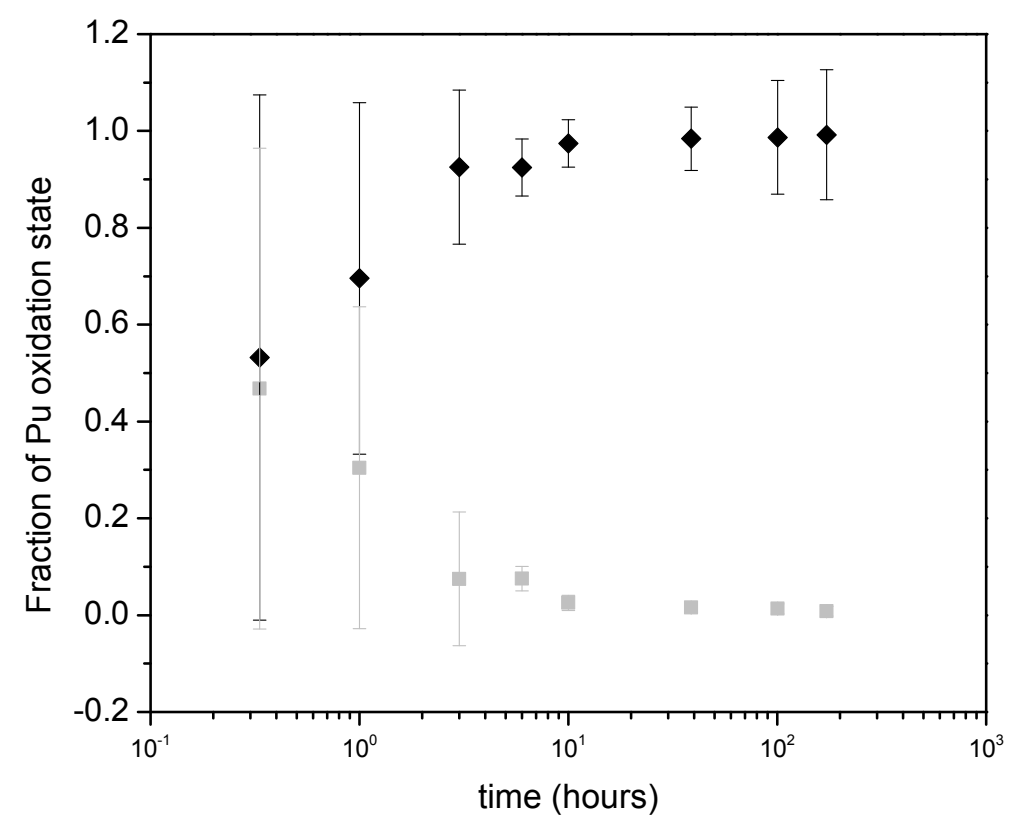

Figure S7: Oxidation state distribution of plutonium $\left({ }^{238} \mathrm{Pu}\right)$ leached from unamended soil (suspended solid $\left.=25 \mathrm{~g} . \mathrm{L}^{-1}\right)$ as a function of sorption time. $\mathrm{Pu}(\mathrm{V})$ fraction is represented by the gray squares and $\mathrm{Pu}(\mathrm{IV})$ fraction by the black diamonds.

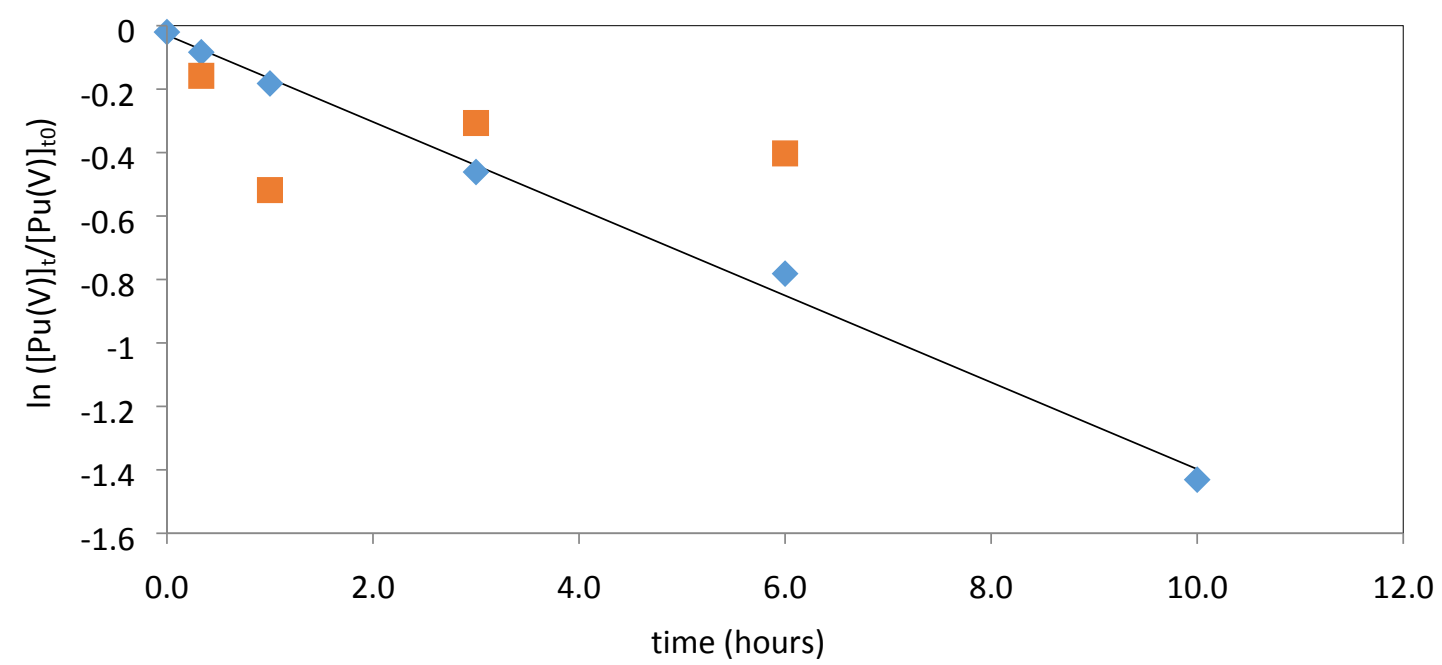

Figure S8: Pseudo-first-order reduction calculation at $\left[{ }^{238} \mathrm{Pu}\right]=10^{-10} \mathrm{M}$ (blue) and $\left[{ }^{242} \mathrm{Pu}\right]=3 \times 10^{-7} \mathrm{M}$ (orange). 

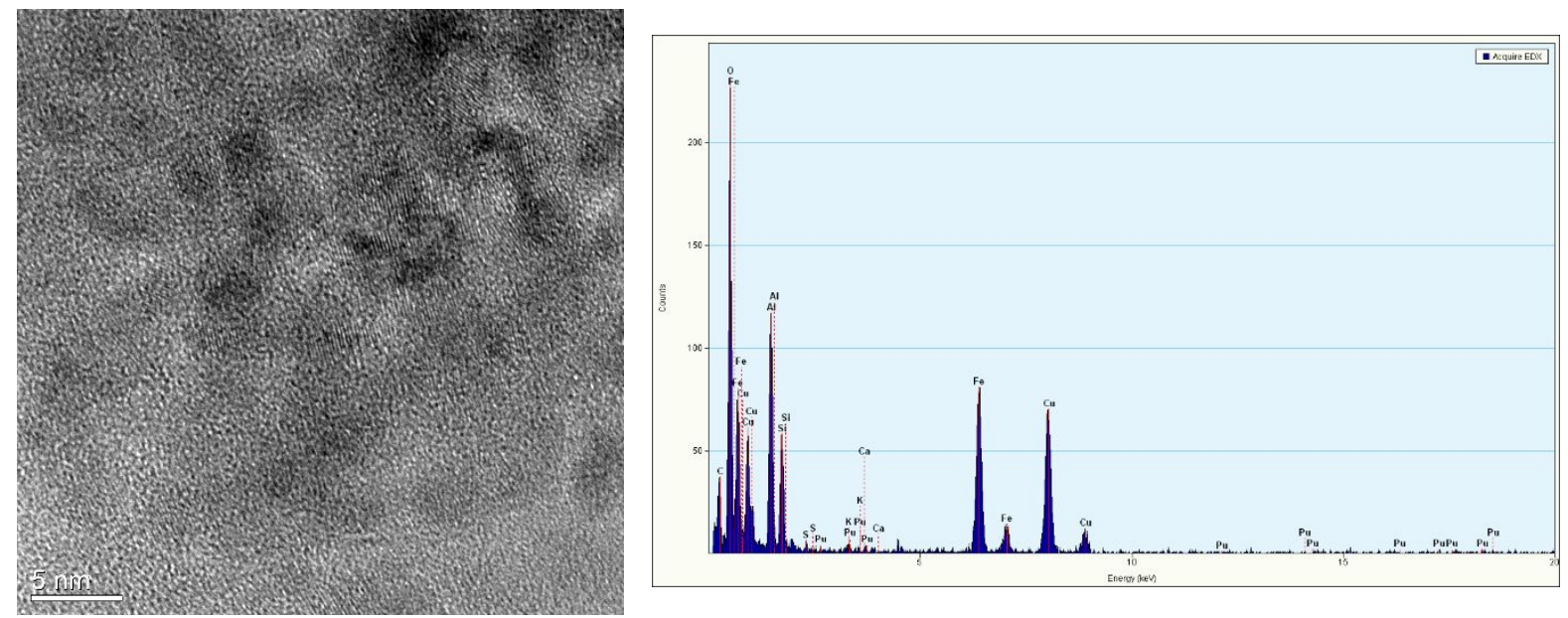

Figure S9: TEM image and associated EDX spectrum of a soil suspension with presence of iron in the phyllosilicates.
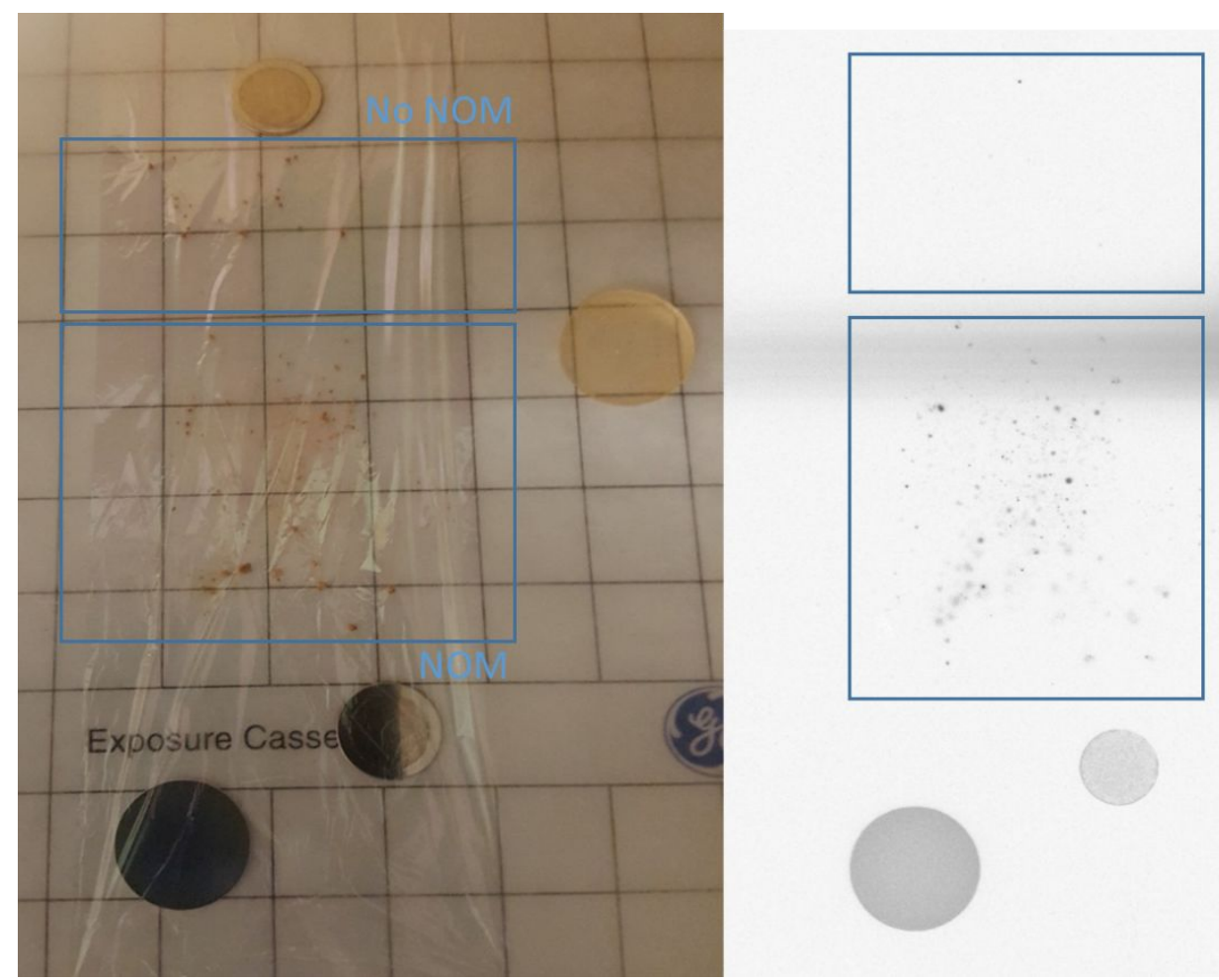

$[\mathrm{Pu}] \sim 300 \mathrm{~Bq} / \mathrm{g}$

$\sim 5 \%$ part. with $\mathrm{Pu}$
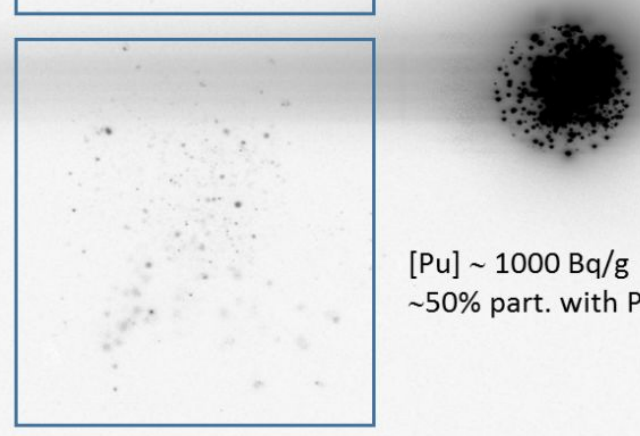

$[\mathrm{Pu}] \sim 1000 \mathrm{~Bq} / \mathrm{g}$

$\sim 50 \%$ part. with $\mathrm{Pu}$

Figure S10: Autoradiogaphy image of soil from lysimeters 


\section{REFERENCES}

1. Kaplan, D. I.; Powell, B.; Demirkanli, D. I.; Fjeld, R. A.; Molz, F. J.; Serkiz, S. M.; Coates, J. T., Influence of Oxidation States on Plutonium Mobility during Long-Term Transport through an Unsaturated Subsurface Environment. Environmental Science and Technology 2004, 38, 5053-5058. 